\title{
Grassland communities of the Mongolian Plateau
}

\author{
Photos and text by Frank Yonghong $\mathrm{Li}^{1}$, Tiejun $\mathrm{Bao}^{1}$, Liqing $\mathrm{Zhao}^{1}$, Wenhong $\mathrm{Ma}^{1}$ \& Jinghui Zhang ${ }^{1}$ \\ ${ }^{1}$ Ministry of Education Key Laboratory of Ecology and Resource Use of the Mongolian Plateau, School of Ecology and Environment, \\ Inner Mongolia, Hohhot 010021, China; e-mail: lifyhong@126.com
}

The Mongolian Plateau is the part of the Central Asian Plateau lying between $37^{\circ} 46^{\prime}-53^{\circ} 08^{\prime} \mathrm{N}$ and $87^{\circ} 40^{\prime}-122^{\circ} 15^{\prime} \mathrm{E}$ with an area of approximately $3,200,000$ square kilometers. It is bounded by the Greater Hinggan Mountains in the east, the Sayan and Khentii Mountains to the north, the Altai Mountains to the west, and the Yin Mountains to the south. It has an elevation of roughly 1,000 to 1,500 meters, with the lowest point in Hulunbuir and the highest point in Altai Mountains. The plateau includes mainly the entire territory of Mongolia, part of the Inner Mongolia and Xinjiang Autonomous Regions of China, and part of the Buryatia and the southern Irkutsk Oblast of Russia. The majority of the plateau is dryland, covered by deserts and steppes, though forests exist in mountainous areas in the northern and eastern parts, and wetlands are scattered here and there.

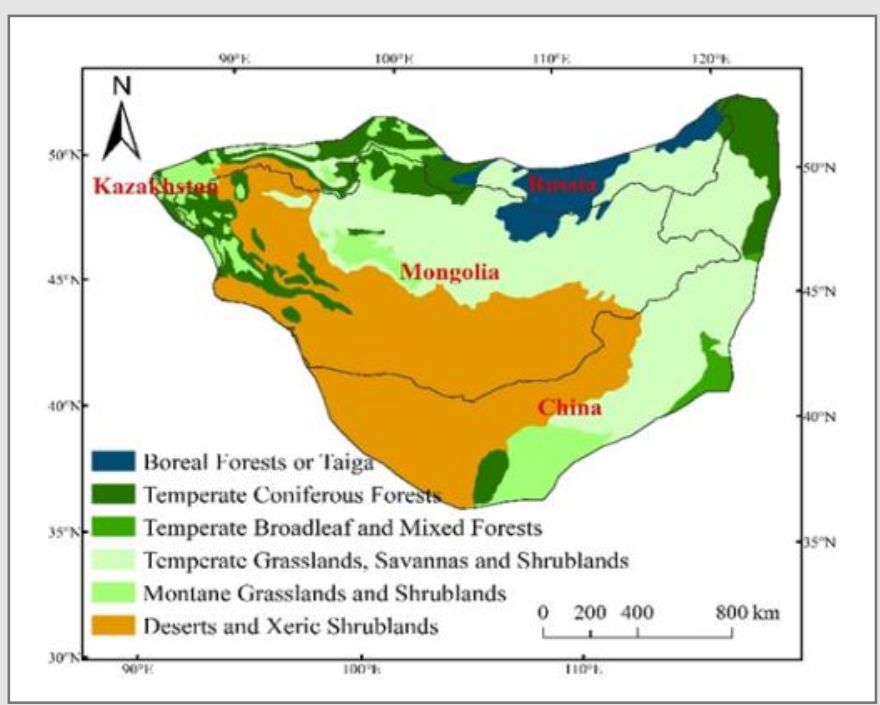

The major biomes on the Mongolian Plateau (extracted from Olson et al. 2001)

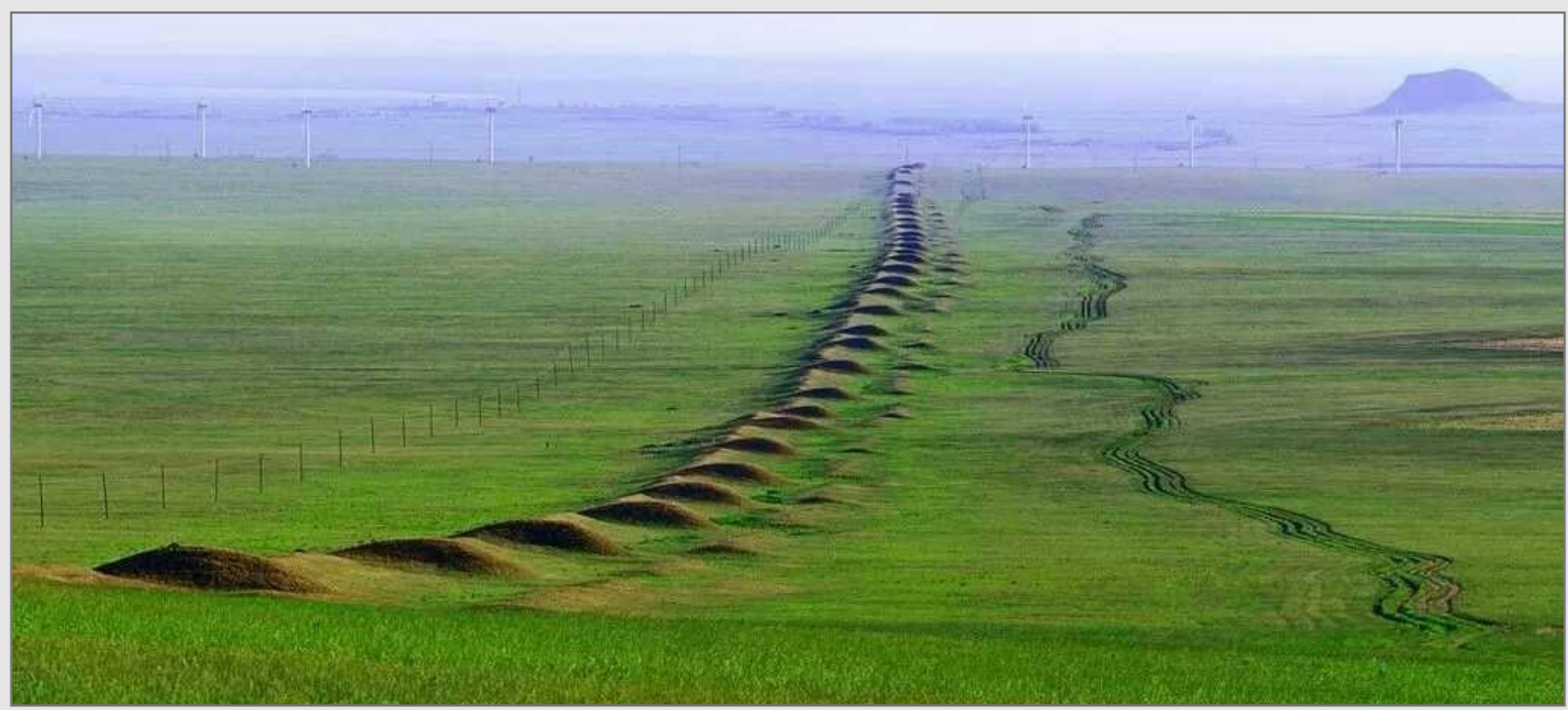

The landscape in the typical steppe region, covered by Leymus chinensis vegetation. The connected hills are the relic of the bordering wall between Nuzhen and Mongolian tribes, built in the 12th century (Jin dynasty of China). Photo: FY. Li. 

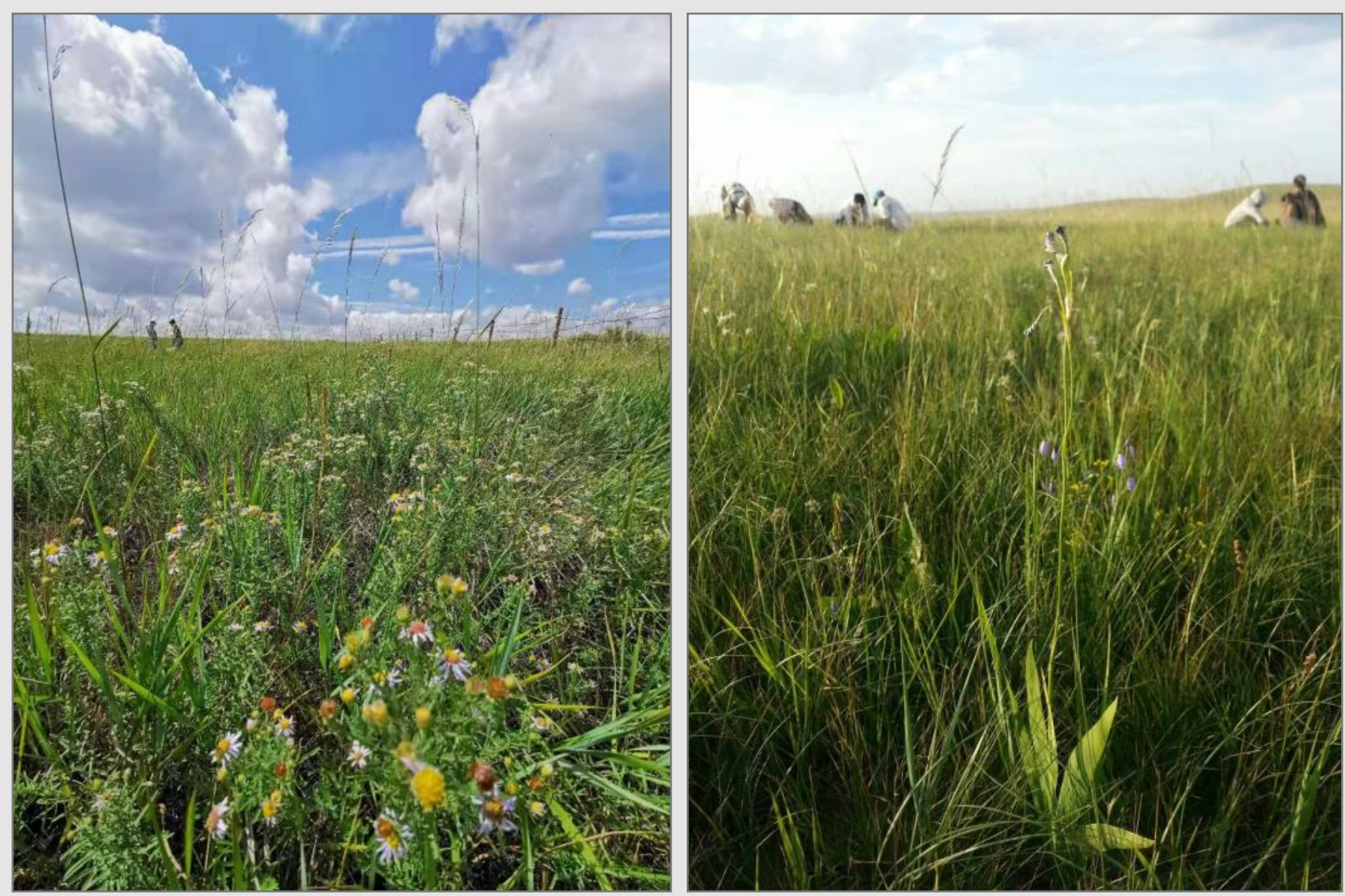

Leymus chinensis community occurs in the relatively humid habitat in the typical steppe zone. It may also form meadow steppe community with meso-xerophytes. The photos show two $L$. chinensis communities, one with a patch of flowering Heteropappus altaicus in front (left), and the other with Iris dichotoma in front, taken in central Inner Mongolia, China. Photos: FY. Li.

The climate is the driest in the central part of the Mongolian Plateau, where desert vegetation is distributed. Apart from the driest Gobi Desert area, humidity increases in all the three directions to the north, east and south in the vast area of the eastern Mongolian Plateau, and the vegetation changes successively into desert steppe, typical steppe and meadow (mountain) steppe, before finally into forest. Here we show the major grassland communities in the vast steppe region of the Mongolian Plateau along a gradient of increasing climatic aridity. More detailed information on these grasslands can be found in Li et al. (2020) and Pfeiffer et al. (2020).

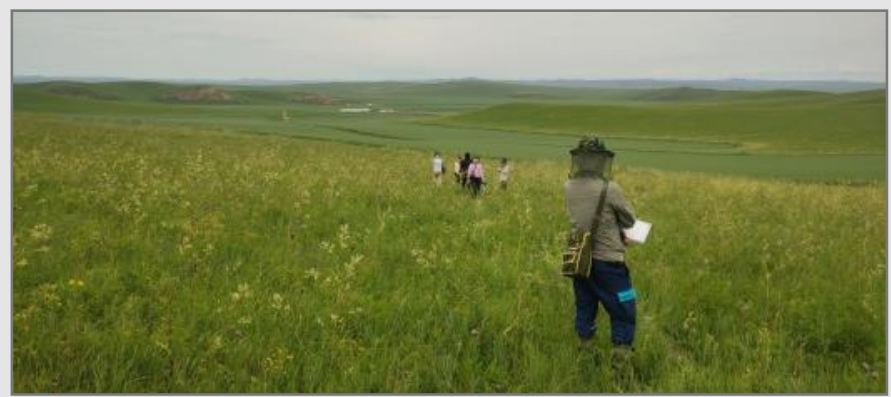

Leymus chinensis + Filifolium sibiricum meadow steppe community in the Ujumchin region (with Polygonum divaricatum). Photo: JH. Zhang.

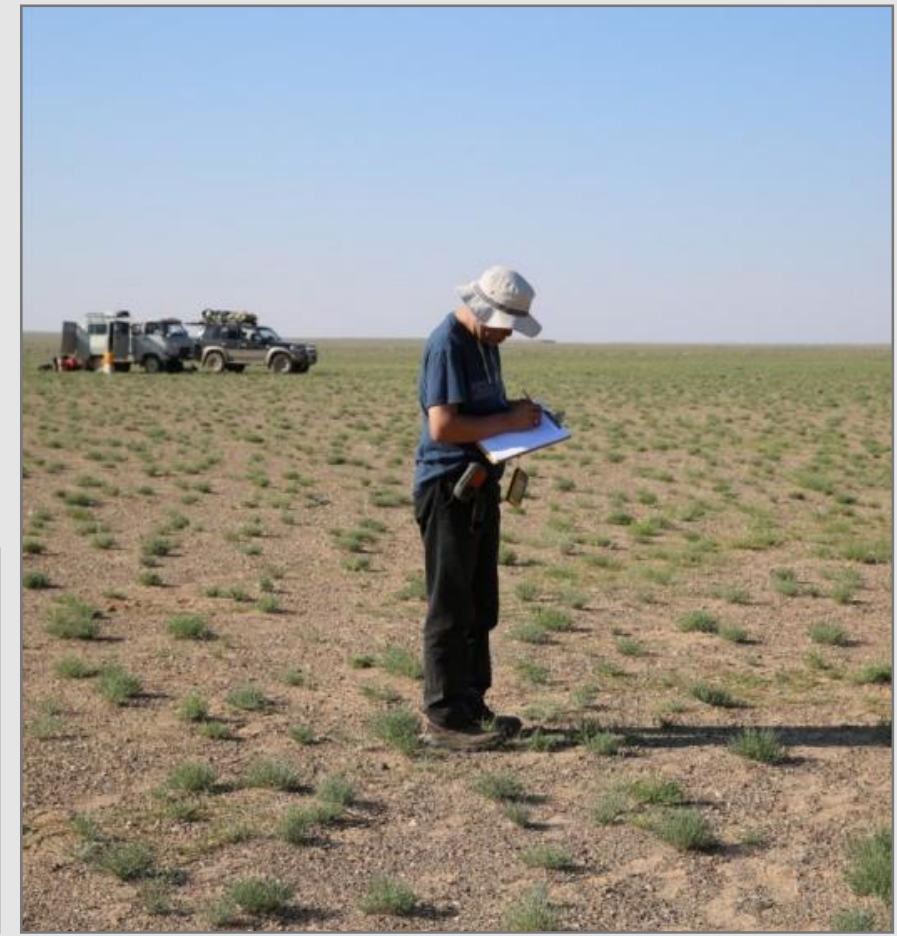

Anabasis brevifolia desert community at the border of China and Mongolia, west to Zamyn-Uud, Mongolia. Photo: TJ. Bao. 


\section{Further reading}

Li, F.Y., Jäschke, Y., Guo, K. \& Wesche, K. 2020. Grasslands of China. In: Goldstein, M.I. \& DellaSala, D.A. (eds.) Encyclopedia of the World's Biomes, vol. 3, pp. 773-784. Elsevier, Amsterdam, NL.

Pfeiffer, M., Dulamsuren, C. \& Wesche, K. 2020. Grasslands and shrublands of Mongolia. In: Goldstein, M.I. \& DellaSala, D.A. (eds.) Encyclopedia of the World's Biomes, vol. 3, pp. 759-772. Elsevier, Amsterdam, NL.

Olson, D.M., Dinerstein, E., Wikramanayake, E.D., Burgess, N.D., Powell, G.V.N., Underwood, E.C., D'amico J.A., Itoua, I., Strand, H.E., (...) \& Kassem K.R. 2001. Terrestrial ecoregions of the world: A new map of life on Earth. BioScience 51: 933-938.

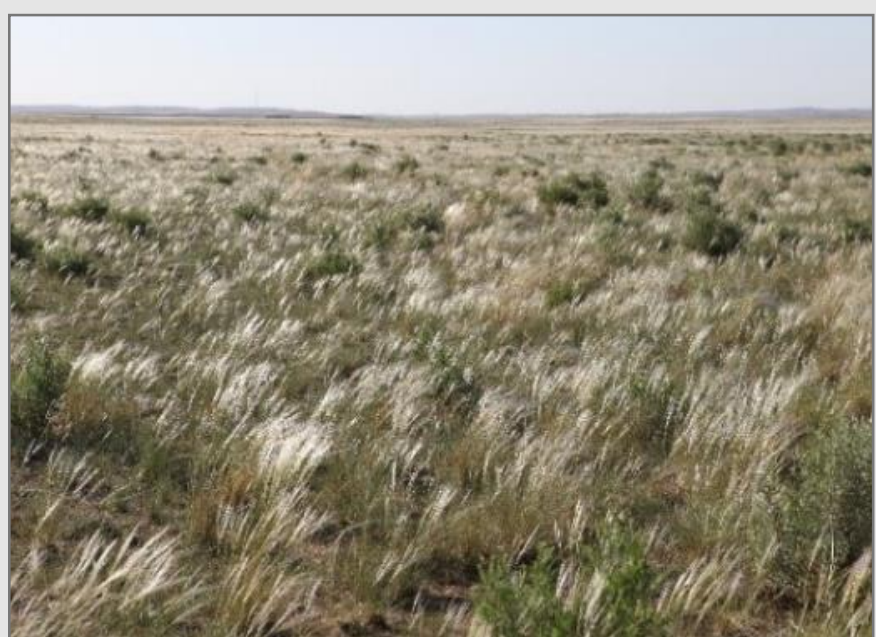

Stipa klemenzii desert steppe community in the Urad region, Inner Mongolia, China. The shrub is Caragana intermedia. Photo: LQ. Zhao.
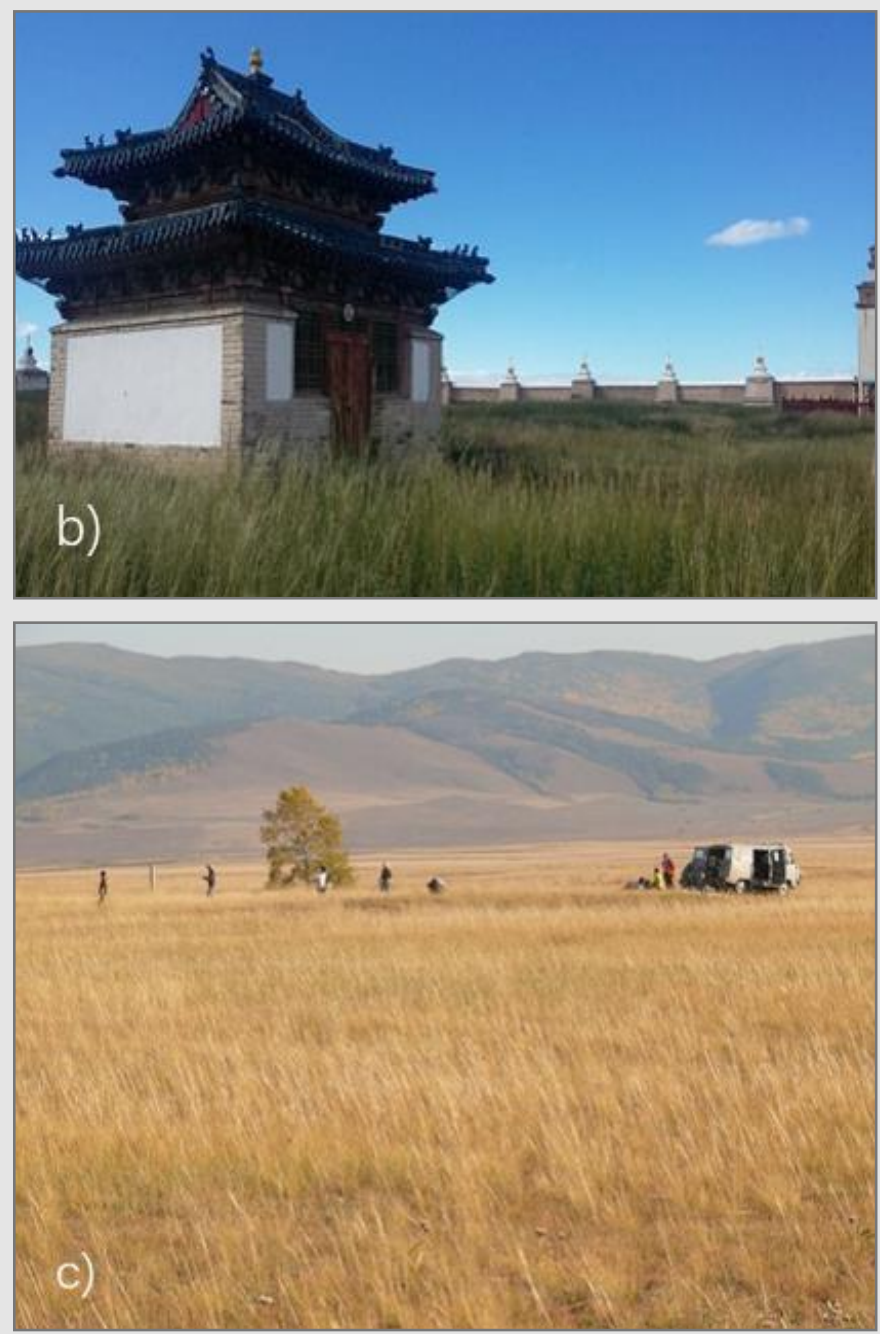

Stipa krylovii community is the most widely distributed Stipa community on the Mongolian Plateau. The photos show (a) Stipa krylovii community in the Abaga region of Inner Mongolia, China, (b) besides the Karakorum historical heritage site in central Mongolia, and (c) in the east bank area of the lake Baikal, Buryatia of Russia. Photos: FY. Li. 

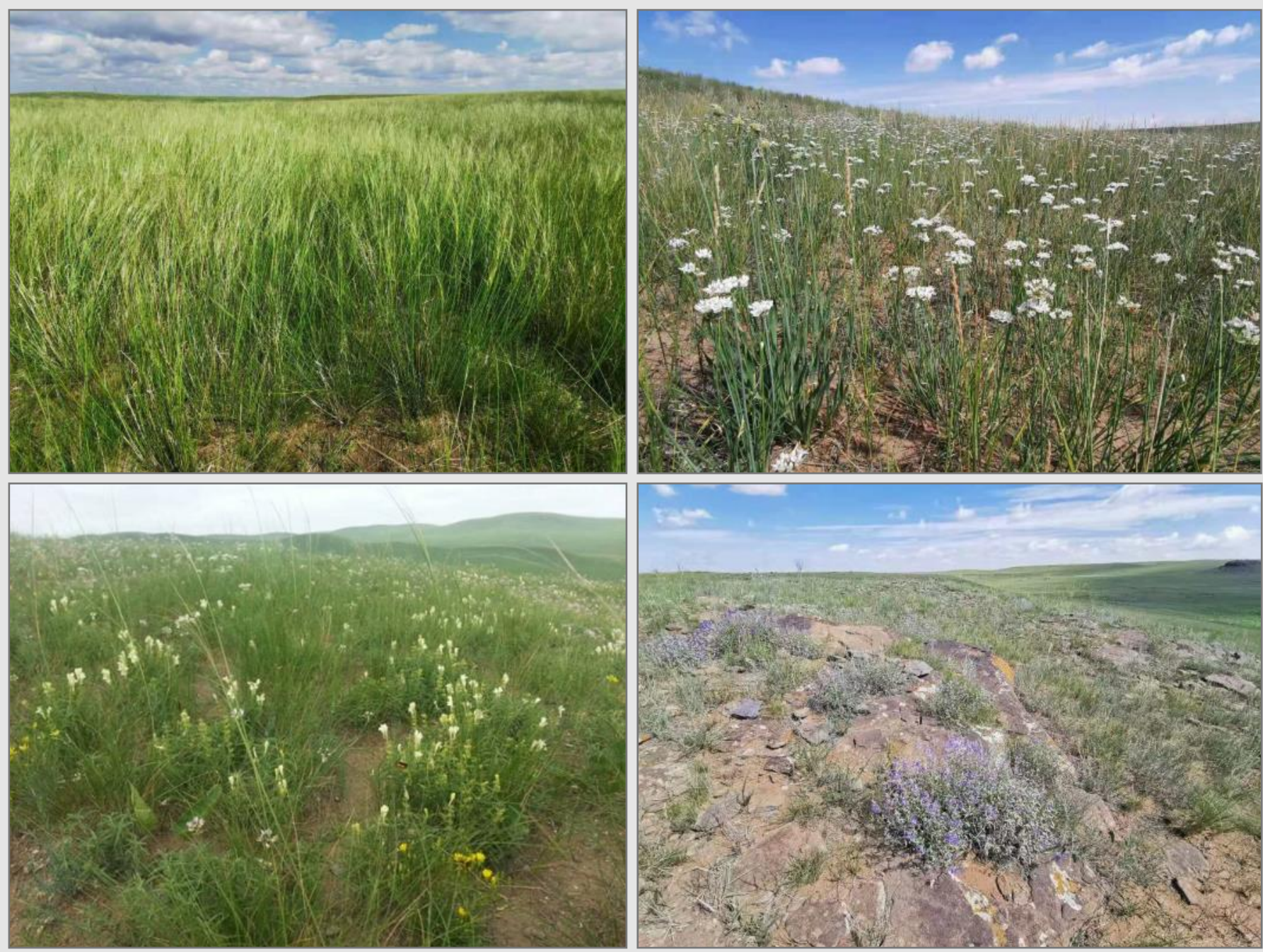

Stipa grandis community is one of the major plant communities in the zonal habitat of the typical steppe zone, although diverse plant communities may develop with the variation in landforms. The four photos show (clockwise): (a) Stipa grandis predominant community in a vast high plain, (b) Allium ramosum community (with one $A$. senescens with broad leaves on the left side) on a sandy slope, (c) Scutellaria viscidula community on a hill top, and (d) Caryopteris mongholica community on a basaltic rocky platform, all in the Xilingol region of Inner Mongolia, China. Photos: FY. Li.
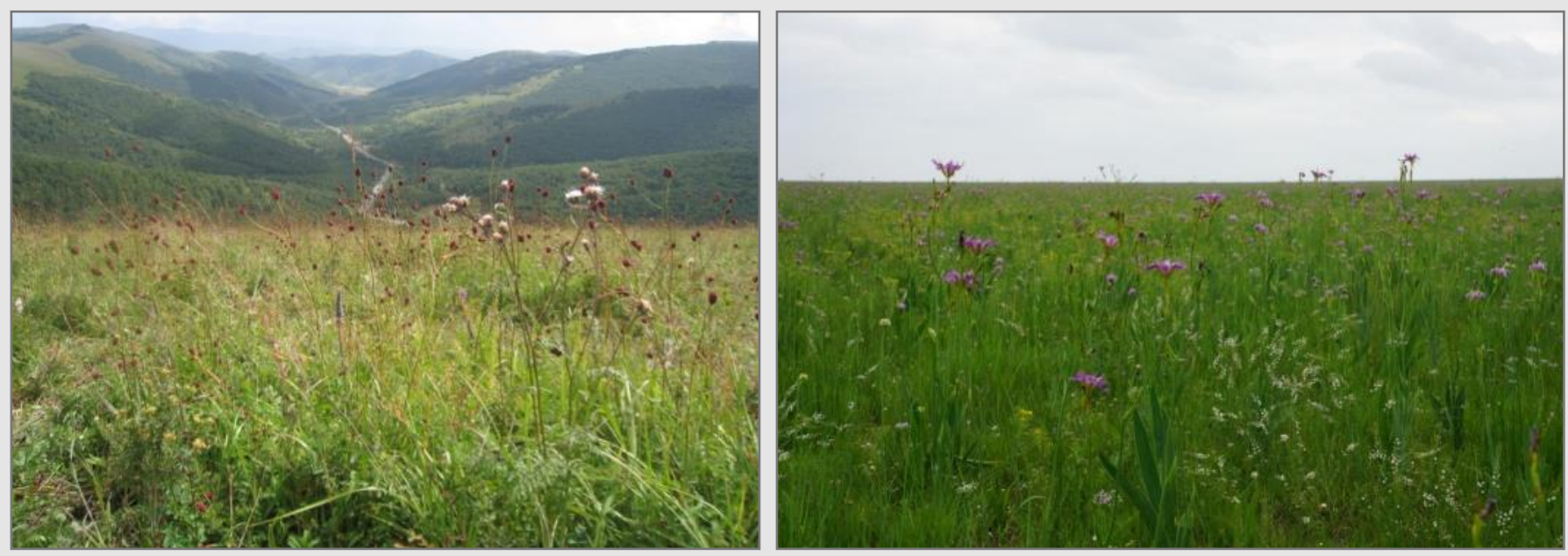

Sanguisorba officinalis meadow community in Chifeng region (left) and species-rich meadow community in Hulunbuir region (right photo), with identifiable Iris dichotoma with pink flower, Filifolium sibiricum with yellow flower and Astragalus melilotoides with white flower, in the forest-grassland ecotone region in the eastern part of the Mongolian Plateau. Photos: FY. Li and WH. Ma. 

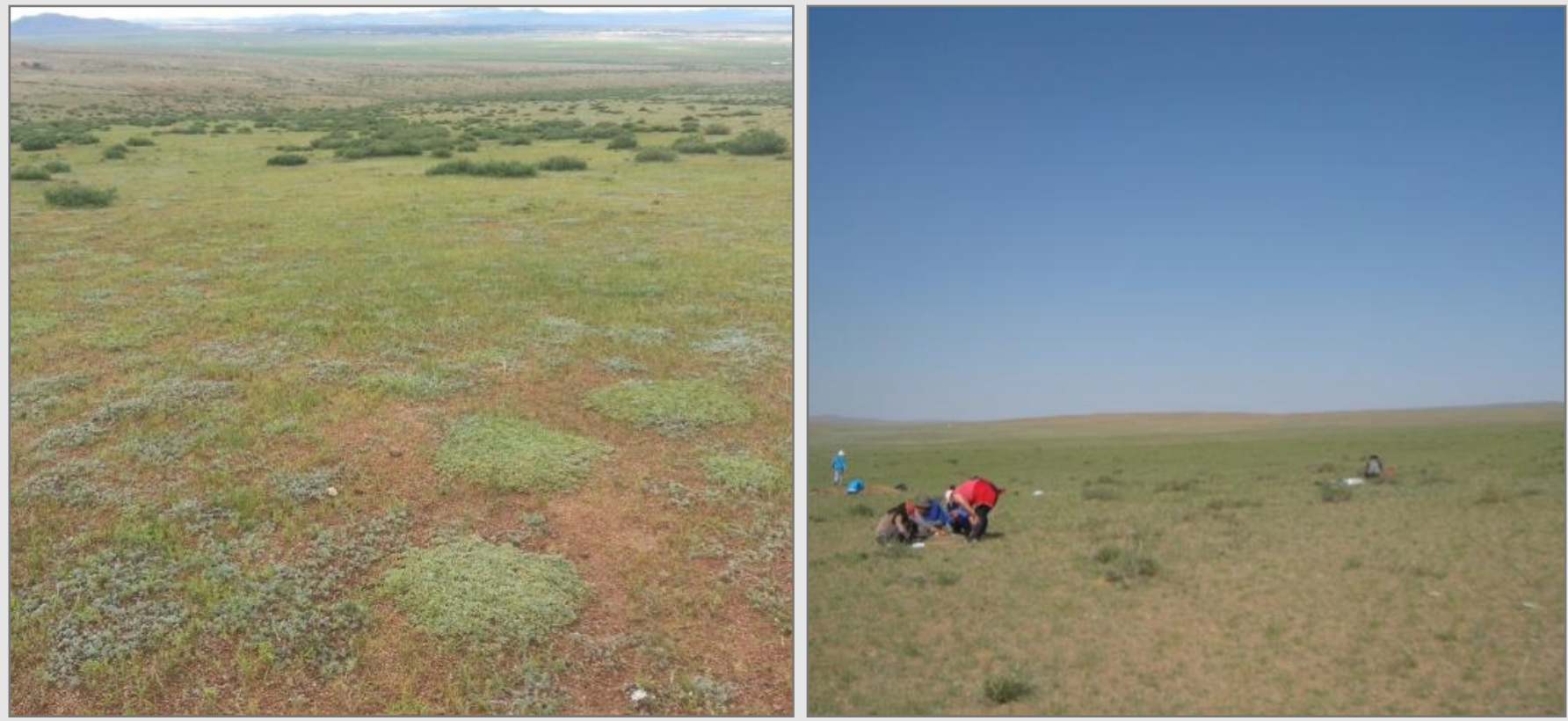

Over-grazing induced grassland degradation is common in the steppes. The Artemisia frigida + Potentilla acaulis community is typical of grassland communities degraded under long-term grazing from the primary Stipa krylovii and Leymus chinensis communities in the steppe region of the Plateau. The photos are taken in the central-north part of Mongolia. Photos: FY. Li.
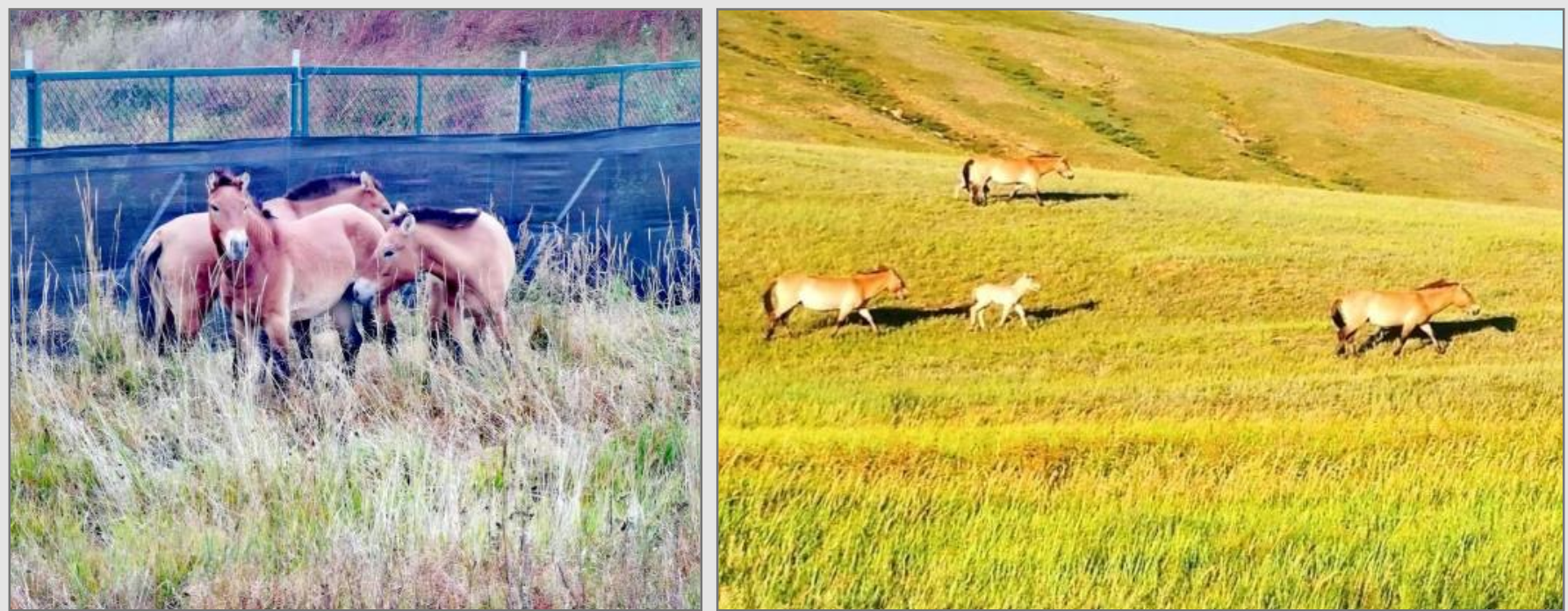

Przewalski's horse (Equus ferus subsp. przewalskii) is the keystone species of the vast steppes of the Mongolian Plateau. The horse was extinct in the fields of the Plateau in the 1940s and was re-introduced from the European zoos. The photos are taken from the Daqinshan National Nature Reserve in China (left) and the Hustai National Park of Mongolia (right). Photos: FY. Li. 